\title{
Author Correction: Hysteresis control of epithelial- mesenchymal transition dynamics conveys a distinct program with enhanced metastatic ability
}

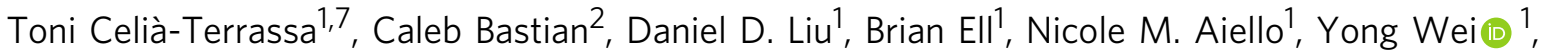 \\ Jose Zamalloa1,3, Andres M. Blanco ${ }^{1}$, Xiang Hang ${ }^{1}$, Dmitriy Kunisky4 ${ }^{4}$,Wenyang Li ${ }^{1}$, Elizabeth D. Williams ${ }^{5}$, \\ Herschel Rabitz ${ }^{2,6} \&$ Yibin Kang ${ }^{1}$
}

Correction to: Nature Communications; https://doi.org/10.1038/s41467-018-07538-7; published online 27 Nov 2018.

The original version of this Article contained an error in the spelling of the author Daniel D. Liu, which was incorrectly given as Daniel Liu. This has now been corrected in both the PDF and HTML versions of the Article.

Published online: 28 January 2019 \begin{abstract}
reproduction in any medium or format, as long as you give appropriate credit to the original author(s) and the source, provide a link to the Creative Commons license, were made. The images or other third party material in this article are included in the article's $\mathrm{C}$ line to the material. If material is not included in the article's Creative Commons license and your intended use is not permitted by statutory regulation or exceeds the permitted use, you will need to obtain permission directly from the copyright holder. To view a copy of this license, visit http://creativecommons.org/licenses/by/4.0/.
\end{abstract}

(c) (i) Open Access This article is licensed under a Creative Commons Attribution 4.0 International License, which permits use, sharing, adaptation, distribution and

(C) The Author(s) 2019

\footnotetext{
${ }^{1}$ Department of Molecular Biology, Princeton University, Princeton, NJ 08544, USA. ${ }^{2}$ Program in Applied and Computational Mathematics, Princeton University, Princeton, NJ 08544, USA. ${ }^{3}$ Lewis-Sigler Institute of Integrative Genomics, Princeton University, Princeton, NJ 08544, USA. ${ }^{4}$ Department of Mathematics, Princeton University, Princeton, NJ 08544, USA. ${ }^{5}$ School of Biomedical Sciences, Translational Research Institute, Queensland University of Technology (QUT), Brisbane, QLD 4102, Australia. ${ }^{6}$ Department of Chemistry, Princeton University, Princeton, NJ 08544, USA. ${ }^{7}$ Present address: Cancer Program, IMIM (Hospital del Mar Medical Research Institute), 08003 Barcelona, Spain. These authors contributed equally: Toni Celià-Terrassa, Caleb Bastian. The original article can be found online at https://doi.org/10.1038/s41467-018-07538-7. Correspondence and requests for materials should be addressed to C.B. (email: cbastian@princeton.edu) or to Y.K. (email: ykang@princeton.edu)
} 